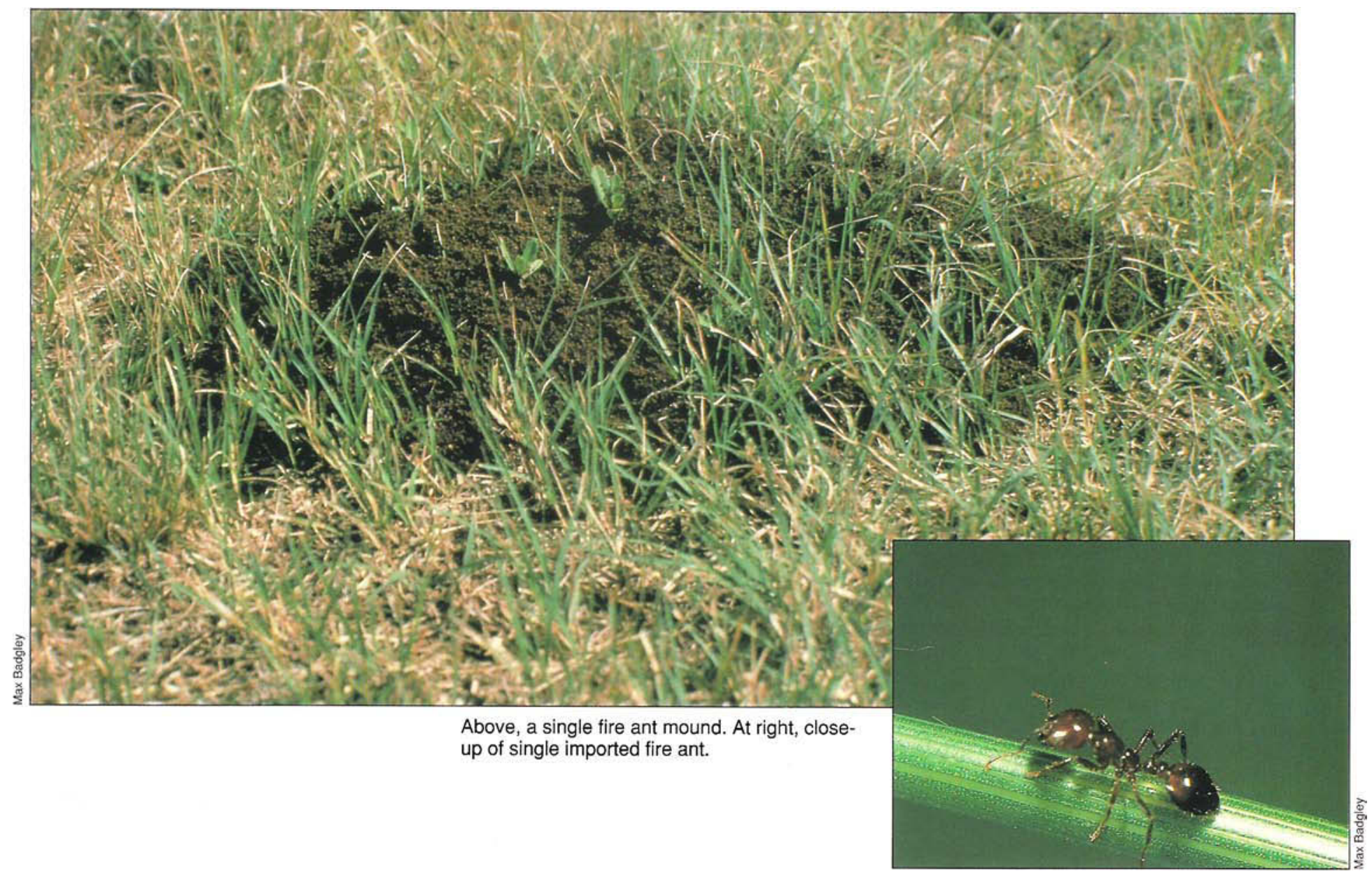

\title{
Imported fire ants: potential risk to California
}

Vernard R. Lewis

口 Laura D. Merrill
Thomas H. Atkinson

Joanne S. Wasbauer

\begin{abstract}
Since the first general detection surveys for imported fire ants in California in 1987, 758 intercepts among the state's 16 border inspection stations have been recorded. One colony discovered at a nursery in Santa Barbara in 1988 was successfully eradicated. With more traffic expected into California, it is likely that interceptions and localized eradication efforts for imported fire ants will increase.
\end{abstract}

Imported fire ants comprise two species, Solenopsis invicta Buren, the red imported fire ant, and S. richteri Forel, the black imported fire ant. Both species are native to
Brazil and Argentina and were probably introduced on multiple occasions into the United States at Mobile, Alabama, between 1918 (initially, only S. richteri) and 1945. The probable source of introduction was ballast or dunnage discarded from cargo ships engaged in commercial trade between Gulf Coast ports and the east coast of South America. Distribution of $S$. richteri is confined to northeastern Mississippi, northwestern Alabama and southwestern Tennessee. Distribution of $S$. invicta is more extensive and includes Louisiana, Mississippi, Alabama, Florida, Georgia, South Carolina and portions of North Carolina, Tennessee, Arkansas, Oklahoma and Texas. Several species of native fire ants occur from the Carolinas across the southern United States into California. However, in contrast to imported fire ants, native species have lower population densities and cause minor problems.

Over the past two decades polygyny has been found to be common in S. invicta nests. The first colonies of imported fire ants found in the United States were thought to have had single queens. However, in 1973 more than 3,000 queens were found in a single nest, dubbed Queen City, in Hurley, Mississippi. Subsequently multiple-queen colonies were found in many parts of the red imported fire ant's range. The total number of reproductives and workers in these multiple-queen nests can be immense, exceeding 250,000 individuals. Because some queens in polygynous colonies have only moderately enlarged abdomens, it is likely that before the discovery of polygyny in this species, many polygynous colonies were overlooked. It is not known if the polygyny commonly 
found today represents a genetic change in the species or is the result of more careful observation.

At first, imported fire ants were thought to require warm environments with high rainfall, perhaps because the most rapid spread occurred in such areas. However, the red imported fire ant has expanded its range into portions of Texas previously thought too dry. Possibly this is because this species only requires rainfall for mating flights and nest initiation by new queens, or perhaps the expanded range presents a fundamental change in the ant's ecology. However, it is still not known whether the imported fire ant will reproduce in areas lacking summer rains, such as in California's Mediterranean climate. Future expansion of this exotic ant pest may include coastal and heavily irrigated areas of California.

\section{Economic impact}

Imported fire ants are primarily predators, but they may attack agricultural crops. They have been reported as pests of agricultural crops in the Southeast, including soybean, eggplant, cotton, corn and okra. These reports are not well substantiated in the literature. Imported fire ants can also affect crops indirectly by tending aphids, thereby interfering with the biological control of these pests by parasitic wasps. Fire ant mounds, which may number as many as 400 per acre, can hamper field operations by clogging or damaging equipment. Other states have reported livestock deaths due to ant stings. Native ant species can also be displaced, along with other arthropod species, when imported fire ants invade an area. However, the effects of imported fire ants on native ant fauna need clarification.

The primary impact of imported fire ants is as nuisance pests because of their painful and aggressive stinging. The stings are highly inflammatory, leaving pustules that can remain for several weeks. Small children are especially vulnerable and are often kept indoors to avoid the risk of stings. In 1982, projected medical costs for infested areas exceeded $\$ 2.8$ million. Tragically, some deaths from imported fire ant stings have been recorded. However, the venom is primarily composed of alkaloids with only traces of protein. Thus, although systemic allergic reactions to the venom do occur, they are rare, particularly in comparison with allergies to other stinging insects such as bees and wasps.

Because of their predaceous behavior, imported fire ants reduce populations of other insect pests. Where these ants are abundant they are thought to be particularly beneficial in managing the cotton boll weevil, Heliothis spp. on cotton, and the lone star tick. These benefits, however, do not outweigh the medical, agricultural and environmental costs of these pests, both through direct damage to native ecosystems and through indirect damage from increased pesticide use.

\section{Interceptions in California}

Discoveries of nests and eradication efforts in Arizona and New Mexico in 1987 heightened concerns about imported fire ant introductions into California. Because of field discoveries outside of the southeastern and Texan containment areas, California began to include imported fire ants in its general detection surveys in 1987.

Survey procedures in California include hand and pitfall traps in 25 central and southern counties. High-risk sites sampled include nurseries, parks, cemeteries, trailer parks, rest areas, truck scales, railroad yards, military installations, oil drilling sites and equipment storage facilities. In total, more than 900 pitfall traps have been deployed. Over the last 5 years (1987-1991), 8,000 field samples have been collected for species determinations by the Analysis and Identification Unit of the California Department of Food and Agriculture. So far no imported fire ants have been identified from pitfall traps nor from hand-collected field samples.

Reports of imported fire ant interceptions at the California border began in 1984 (fig. 1a). Interceptions at border stations remained below 100 per year until 1989. During the 1989-1990 fiscal year, interceptions increased to 354 . The reason for the sudden increase is unknown. Some ant specialists speculate, however, that heavy rains at the sources of origin may have forced ant colonies to aggregate in dry, aboveground locations, including trucks en route to California. Interceptions last year numbered 170. During the first 4 months of the fiscal year 1991-92, 112 interceptions were reported and 7 nests were found in trucks entering the state from Alabama, Georgia and Texas. An analysis of border station interception data by month reveals that fire ant occurrence peaks in spring and summer (fig. 1b). However, this finding may only reflect travel trends since traffic recorded at border stations is also highest during those months. Traffic into California last year totaled 26 million autos and trucks and has been increasing at a rate of $10 \%$ per year.

Most imported fire ants intercepted at border stations were in nonagricultural shipments, such as pallets, roofing materials and carpets (fig. 2). Some unusual interceptions were in trucks loaded with pesticides. Nursery stock, at least for now, was relatively low on the list of sources. Even with low interception numbers in nursery stock, these may be biologically most significant since imported fire ant colonies may be moved intact. Recently, nursery stock importations into the state have increased due to the freeze of December 1990, which killed many Southern California semi-tropical plants, especially palm trees. With increasing frequency, attempts are being made to smuggle contraband palms into the state. The root balls of these landscape materials could be the means for imported fire ant colonies to enter California. The frequency with which

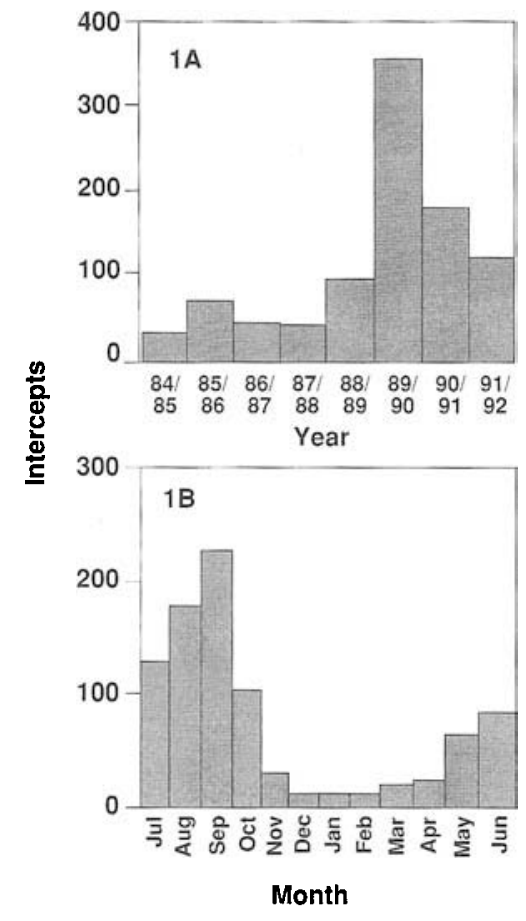

Fig. 1A-B. Interceptions of Solenopsis spp. by year (1A) and month (1B) at California border stations. Intercepts for 1991-92 are incomplete and only include the months of July to October, 1991. Monthly data represent sum totals for ail interceptions since 1987. Data were provided by the Pest Detection and Emergency Projects Unit, CDFA, Sacramento.

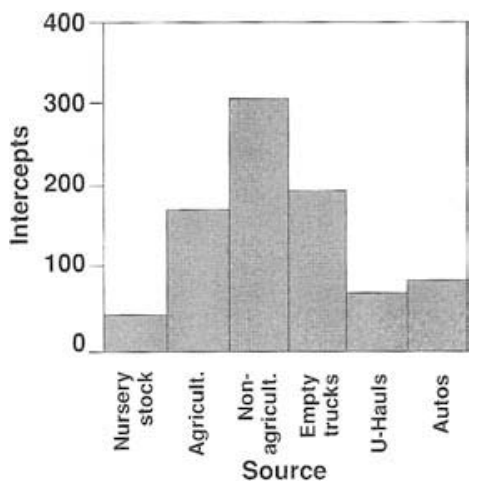

Fig. 2. Sources of imported fire ants into California. Totals represent 758 interceptions since July, 1987. Data provided by the Pest Detection and Emergency Project Unit, CDFA, Sacramento. 
commercial trucks and rental trailers harbor imported fire ants also attests to the invasive potential of this ant pest.

To date, one eradication effort has been directed against imported fire ants in California. A colony of red imported fire ants was discovered at a nursery during $\mathrm{Au}-$ gust 1988 in Santa Barbara County. After an intensive search of the 3-acre nursery, alates (reproductives) as well as major and minor workers were found. The search was expanded to include a 20-acre area around the nursery. Only a single imported red fire ant worker was found off the original nursery site. Chemical treatments and bait applications were subsequently made on the nest and surrounding grounds at the nursery in September 1988. Since that time, inspectors have found no live imported red fire ants.

\section{Potential economic impact}

The almost 2 million acres of irrigated farmlands in California are at greatest risk from imported fire ant introductions. Damage to seedlings, the girdling of small trees, and damage to plowing and harvesting equipment significantly threaten farming and orchard practices. Aggressive stinging by the ants would increase labor costs in the many California crops requiring intensive manual labor. The cost to California's $\$ 18$ billion agricultural economy is difficult to predict and depends on how widespread the ants become once established.

With a population of 30 million, California is developing into a diverse mixture of people, structures, landscapes and wildlife. California's nonagricultural irrigated landscapes - home lawns, golf courses, parks, freeway plantings, athletic fields, etc., - now exceed 1 million acres. Costs of maintaining this landscape, already $\$ 10$ billion annually, would go up if imported fire ants become established. Damaged landscape replacement costs, damaged lawn care equipment costs, and medical and lost labor costs are anticipated to increase. Structural and household pest control costs, already in excess of $\$ 300$ million per year statewide, could also increase substantially. In the southeastern United States, red imported fire ants are major pests in lawns and invade homes. Established indoor infestations have been documented in potted plants. Short circuits to electrical systems can occur because of the strong attraction of imported fire ants to electric fields. Allergic reactions to stings by these ants represent a public heath risk. An additional economic concern is decreased real estate values, already occurring in imported fire ant-infested areas of other states. The 300 native California species of mammals, birds, reptiles and amphibians could also be at risk from im- ported fire ant introductions. Reports from other states include deaths of the young of small ground-nesting birds, rabbits and reptiles, and predation on native invertebrates. Effects on populations of native wildlife are unknown.

\section{Prospects for control}

From 1957 to 1981 , an estimated \$172 million has been spent on imported fire ant control in the southeastern United. States. Initial control strategies relied on the use of heptachlor and dieldrin, and later, Mirex baits. However, in 1976 the U.S. Environmental Protection Agency cancelled the registration of Mirex because of bioaccumulation in the environment, carcinogenicity in laboratory studies, and potential long-term hazards to wildlife. Since that time, 92 products of 4,000 tested have been approved and marketed for imported fire ant control. Of those materials commercially available, three are baits. Two are chemical insecticides, hydramethylnon (Amdro) and abamectin (Affirm). Fenoxycarb (Logic) is an insect growth regulator (IGR). None is registered for use in California. Baits actually work well and are safe. These baits can be broadcast, efficiently treating large areas. Logic (IGR) and Amdro (active ingredient breaks down in sunlight within 24 hours) are safe and environmentally benign. All current baits are slow acting, allowing the active ingredient to be widely distributed among workers, brood and the queen. Bait treatments tend to be more effective over large areas than direct nest treatments. These baits, however, are not species-specific and would also kill native ants where the baits are used. Some researchers believe that the killing of native competitors by Mirex increased the rate of spread of $S$. invicta.

Several contact insecticidal drenches, dusts and aerosols are registered and marketed in the southern United States for imported fire ant control. These chemicals are acephate, bendiocarb, carbaryl, chlorpyrifos, diazinon, malathion, pyrethrins and certain pyrethroids. Contact poisons are fast-acting and often are used to drench nests or fend off home-invading columns of fire ants. However, more intensive treatment is often required. Nonchemical control prospects are limited. Control attempts using hot water have been shown to be an effective home remedy. On the other hand, nematodes, fungi and the physical removal of nests have not been effective.

\section{Potential for establishment in state}

Available research has shown that imported fire ants require warm summer rains for nuptial flights to occur. In the absence of such rains, alate reproductives may be present in the nests, but these alates will not mate and disperse to found new colonies. An experiment has shown that overhead sprinkling is not adequate to stimulate mating flights. In part for this reason, some experts doubt that imported fire ants will become established in California unless there is an unforeseen global climate change.

Newly mated queens alight and dig burrows for rearing their first broods. Because successful nest construction occurs in moist soil, the large acreages of irrigated farmland and lawns and other landscaped areas in California are suitable for nest building. It is likely that the colony discovered in Santa Barbara in 1988 was founded by a newly mated queen which hitchhiked on a vehicle or had already initiated a small colony in soil, possibly around a root ball, and was not detected at the border.

It is likely that similar isolated colonies will be found again in California. As long as there are no summer rains to stimulate mating flights, and as long as imported fire ants do not fundamentally change their biology, single colonies can readily be killed. However, should mating flights occur in California, it is unlikely that eradication would be successful.

\section{Conclusions}

The actual economic impact of imported fire ants on California's agricultural and urban habitats is difficult to predict because of the drastic environmental contrasts between the arid Mediterranean habitats of the West Coast and the hot and humid conditions common throughout the Southeast. What does appear likely is that imported fire ants will reach California's border stations in increasing numbers and future eradication efforts may be needed.

V.R. Lewis is Assistant Extension Entomologist, Department of Entomological Sciences, UC Berkeley; L. D. Merrill is Entomologist, Forest Pest Management, USDA Forest Service, San Francisco; T. H. Atkinson is Assistant Professor, Department of Entomology, UC Riverside; and J. S. Wasbauer is Associate Economic Entomologist, Exotic Pest Analysis Unit, Division of Plant Industry, CDFA, Sacramento.

The authors thank Don Henry and Richard L. Penrose, Pest Detection/Emergency Projects; Rollin R. Brown, Pest Exclusion Branch; and Marius Wasbauer, Analysis and Identification Branch, all of CDFA, for their assistance. We also thank Barbara Barr, Cooperative Extension, UC Berkeley, for reviewing an earlier version of this manuscript.

Use of trade names is for convenience only and in no way implies endorsement of the products mentioned. 